\title{
Lipid Production Combined with Removal and Bioaccumulation of Pb by Scenedesmus sp. Green Alga
}

\author{
Thanh-Luu Pham ${ }^{1}$, Thanh-Son Dao ${ }^{2}$, Hiep Nghia Bui ${ }^{3}$, Tuyen Kim Nguyen Pham ${ }^{4}$, \\ Tran Thi Huyen Ngo ${ }^{4}$, Ha Manh Bui ${ }^{4,5 *}$ \\ ${ }^{1}$ Ho Chi Minh City University of Technology (HUTECH), Ho Chi Minh City, Vietnam \\ ${ }^{2}$ Institute of Tropical Biology, Vietnam Academy of Science and Technology (VAST), Ho Chi Minh City, Vietnam \\ ${ }^{3}$ Department of Environmental Engineering, Dayeh University, Changhua, Taiwan \\ ${ }^{4}$ Department of Environmental Sciences, Saigon University, Ho Chi Minh City, Vietnam \\ ${ }^{5}$ NTT Institute of High Technology, Nguyen Tat Thanh University, Ho Chi Minh City, Vietnam
}

Received: 13 March 2019

Accepted: 9 May 2019

\begin{abstract}
Microgreen algae have high potential to remove heavy metals from wastewater and to produce biodiesel. In this study, the green algal species Scenesesmus sp. was used to examine the metal uptake and lipids accumulation. The microalga Scenedesmus sp. was grown under continuous regime in the presence of lead $(\mathrm{Pb})$ at concentrations of $0.05,0.5,1,2$ and $10 \mathrm{mg} / \mathrm{L}$ in a laboratory scale system. All treatments were conducted using autoclaved aqueous solution. Results indicated that $\mathrm{Pb}$ inhibited the algal growth with $96 \mathrm{~h}-\mathrm{EC}_{50}$ of $4.76 \mathrm{mg} / \mathrm{L}$. However, the green alga Scenedesmus sp. could efficiently remove $\mathrm{Pb}$ at low concentrations. Lipid accumulation was significantly increased by up to $31 \%$ with the addition of $\mathrm{Pb}$ at up to $1 \mathrm{mg} / \mathrm{L}$. In contrast, lower heavy metal removal efficiencies and decreasing lipid accumulation were observed in the treatment with the highest concentrations of $\mathrm{Pb}(10 \mathrm{mg} / \mathrm{L})$.

Results demonstrate that $\mathrm{Pb}$ concentrations at above $2 \mathrm{mg} / \mathrm{L}$ inhibits the algal growth and subsequently reduces lipid content accumulation in the cell. The present study indicates that the green alga Scenedesmus sp. has the ability to remove $\mathrm{Pb}$ from aqueous media and accumulate lipid content, which could be applied in wastewater treatment technology and biodiesel production
\end{abstract}

Keywords: heavy metal, bioremediation, lead contamination, lipid accumulation.

*e-mail: pt.luu@hutech.edu.vn or manhhakg@sgu.edu.vn 


\section{Introduction}

Agriculture and industrial activities has greatly increased the input of heavy metal into bodies of water [1]. Even at low concentrations heavy metal ions such as lead, copper and cadmium can be toxic to humans. Lead $(\mathrm{Pb})$ is one of the most commonly used metals in the world. It is highly toxic and causes intellectual and behavioral deficits, impaired hand-eye coordination, and lowered performance in intelligence tests in children.

Recent studies have reported other effects of lead exposure, such as hypertension, cardiovascular problems and renal disease. Chronic exposure to Lead in adults has led to decreased fertility, cataracts, nerve disorders, muscle and joint pain, and memory or concentration problems [2]. Bioaccumulation of heavy metal in aquatic systems and food chains can transfer to higher trophic levels and cause major health problems. Many techniques such as reverse osmosis, electrophoresis, ultra-ion exchange, chemical precipitation, and phytoremediation have been developed to remove heavy metals from contaminated water. However, all these methods have shown disadvantages such as incomplete metal removal, cost and high energy requirements [3].

In addition, the energy crisis has created pressing issues of the $21^{\text {st }}$ century [4]. Fossil fuel reserves have been predicted to be depleted within 60 years [5]. There is requirement for innovative methods of wastewater treatment and exploitation of novel energy forms. Microalgae have attracted considerable attention due to their ability to remove various heavy metals from wastewater $[1,6]$ and their great potential in producing biodiesel [7]. Therefore, the coupling deals of advanced wastewater treatment and biofuel production based on microalgae is a promising solution [4]. The green alga Scenedesmus sp. has proved to be one of the most promising tools to both remove inorganic nutrients from wastewater and to produce biodiesel [8].

Previous studies have been performed on metal removal by microalgae - both living and nonliving [3, 9]. Several species have been found to be very effective in adsorbing heavy metals from aqueous solutions. The ability to remove cadmium and copper from water by living and nonliving green alga Scenedesmus abundans has been reported by Terry and Stone (2002) [9]. These authors suggest that adequate biological treatment of heavy metal-contaminated water based on S. abundans is possible at high algae concentrations. In addition, Zhou et al. (2012) [10] report that several green algae such as Chlorella spp. and Scenedesmus spp. were effective in removing zinc and copper from aqueous solutions, with the highest removal efficiency being near $100 \%$. Other microalgae including cyanobacteria such as Spirulina and Phormidium, diatom such as Phaeodactylum, Nitzschia and Skeletonema have also reported to be potentially effective for phytoremediation of heavy metals from contaminated water and soil [11]. Therefore, there are likely to be many uninvestigated algae species with high ability to remove toxic metal from the natural environment.

In Vietnam, there is severe lead contamination in air, water, soil and crops, with the highest levels of more than 1,000 times that deemed safe being found in the surface [12]. However, removing lead from contaminated sources remains challenging. In this study, the green alga Scenesesmus was isolated from the Nhieu Loc-Thi Nghe Canal, a polluted waterway in Ho Chi Minh City. It was then used to study lipid accumulation and the biosorption and bioaccumulation of $\mathrm{Pb}$ from an aqueous solution.

\section{Experimental}

\section{Alga Isolation and Cultivation}

The green alga species Scenedesmus sp. (Fig. 1) was morphologically identified under a light microscope (Olympus, Tokyo, Japan). The alga was isolated from the Nhieu Loc-Thi Nghe Canal in Ho Chi Minh City and maintained as pure unialgal in COMBO medium [13]. Erlenmeyer flasks $(500 \mathrm{~mL})$ containing $300 \mathrm{~mL}$ medium were used as reactors for cultivation. All cultures were grown on a $12 \mathrm{~h}: 12 \mathrm{~h}$ light:dark cycle at $28 \pm 1^{\circ} \mathrm{C}$ under light intensity of $50 \mu \mathrm{mol}$ photons $/ \mathrm{m}^{2} \mathrm{~s}$ provided by cool white fluorescent tubes.

\section{Biosorption and Bioaccumulation Experiment}

Stock solutions $1000 \mathrm{mg} / \mathrm{L}$ of lead $\mathrm{Pb}\left(\mathrm{NO}_{3}\right)_{2}$ (Titrisol, Merck, Germany) were diluted to concentrations of 0 , $0.05,0.5,1,2$ and $10 \mathrm{mg} / \mathrm{L}$, which were used in the biosorption and bioaccumulation experiments. Lead was spiked with required concentrations in Erlenmeyer flasks $(500 \mathrm{~mL})$ containing $300 \mathrm{~mL}$ culture medium, and living stock of Scenedemus sp. was added to the initial

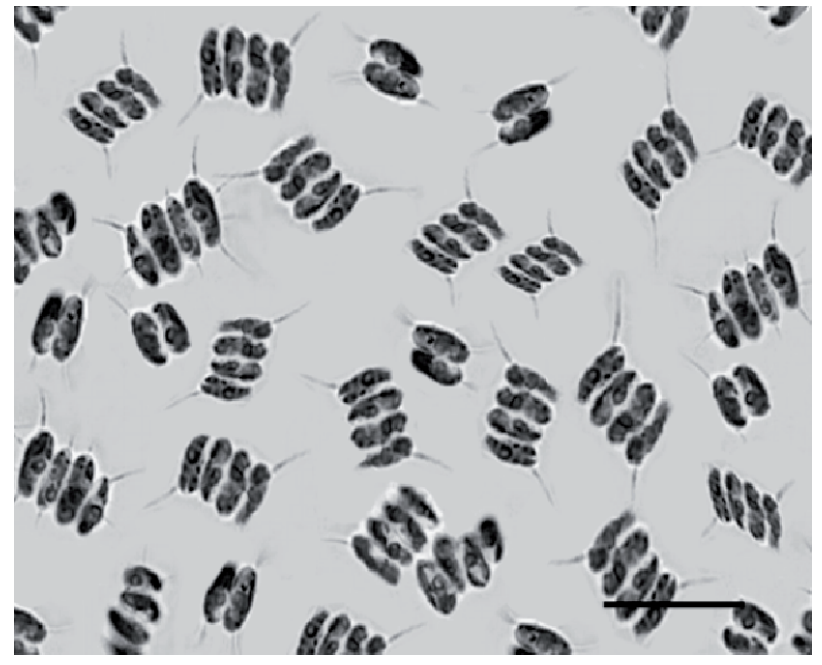

Fig. 1. Morphology of Scenedemsus sp. under microscope; scale bar: $20 \mu \mathrm{m}$. 
concentration of $5 \times 10^{3}$ cell $/ \mathrm{mL}$. Samples were taken at one-day intervals for a period of 7 days. Cell density was estimated directly with a Speirs-Levy Eosinophil counting slide under an Olympus light microscope. At the end of the experiment cells were harvested by filtering onto $\mathrm{GF} / \mathrm{C}$ glass fibre filters (Whatman, Kent, England), dried at $80^{\circ} \mathrm{C}$ overnight and kept at $-20^{\circ} \mathrm{C}$ before analysis. Erlenmeyer flasks with Scenedesmus sp. but without $\mathrm{Pb}$ were used as controls. All treatment was prepared in triplicate.

$\mathrm{The} \mathrm{Pb}$ concentration that inhibits algal growth rate by $50 \%$ over $96 \mathrm{~h}\left(\mathrm{EC}_{50}-96 \mathrm{~h}\right)$ was determined based on the relative inhibition of growth rate as a function of the AgNP concentration $(\mathrm{mg} / \mathrm{L})$. The average of the specific growth rate for each period was obtained as the biomass increase after $96 \mathrm{~h}$, by the following equation:

$$
\mu_{i}-j=\frac{\ln C j-\ln C i}{t_{j}-t_{i}}
$$

...where $\mu_{i-j}$ is the average specific growth rate from time $i$ to time $j, t_{i}$ is the initial time of the exposure period, $t_{j}$ is the final time of exposure, $\mathrm{C}_{i}$ is the concentration of cells at time $i$ and $\mathrm{C}_{j}$ is the concentration of cells at time $j$.

Percentage inhibition of growth was calculated as:

$$
\% \operatorname{Ir}=\frac{\mu_{C}-\mu_{T}}{\mu_{C}} \times 100
$$

...where $\% I r$ is the percentage inhibition in average specific growth rate; $\mu_{C}$ is the mean value for average specific growth rate $(\mu)$ in the control group and $\mu_{T}$ is the average specific growth rate for the treatment replicate.

\section{Total Lipid Fraction Extraction and Measurement}

The total lipid fraction in the algal biomass was extracted according to Bligh and Dyer's method [14] and analyzed using gravimetric quantification methods according to the procedure of Han et al. (2011) [15]. Briefly, a $50-\mathrm{mL}$ centrifuge tube $\left(\mathrm{M}_{0}\right)$ was washed and weighed after drying, $30 \mathrm{mg}$ dry weight (DW) of alga biomass $\left(\mathrm{M}_{1}\right)$ was digested with $3 \mathrm{~mL} \mathrm{HCl} 1 \mathrm{M}$ at $80^{\circ} \mathrm{C}$ for $30 \mathrm{~min}$, and liquid supernatant was discarded after centrifugation. The lipid was then extracted with $3 \mathrm{~mL}$ methanol: chloroform $(2: 1 \mathrm{v} / \mathrm{v})$. After $3 \mathrm{~h}$, the chloroform layer was transferred to a culture dish that had been pre-weighed $\left(\mathrm{M}_{2}\right)$. The dish was then dried completely and re-weighed $\left(\mathrm{M}_{3}\right)$. Lipid content (LC) was calculated according to the following formula:

$$
L C(\%)=\frac{M_{3}-M_{2}}{M_{1}-M_{0}}
$$

\section{Heavy Metal Extraction and Measurement}

Lead content in the algal biomass was homogenized in $5 \mathrm{~mL}$ of concentrated nitric acid (70\%). After sonication for $3 \mathrm{~min}$, the samples were completely digested for $12 \mathrm{~h}$ at $80^{\circ} \mathrm{C}$. The digested samples were then centrifuged at $4000 \mathrm{rpm}$ for $10 \mathrm{~min}$ under room temperature. The supernatant contained metals were kept at $-20^{\circ} \mathrm{C}$ period to analysis. Lead concentration was measured according to the method of dos Santos et al. (2014) [16] with minor modifications. Briefly, an inductively coupled plasma optical emission spectrometer (ICP OES) with axially viewed configuration (VISTA PRO, Varian, Mulgrave, Australia) equipped with a solid state detector, a cyclonic spray chamber, and a concentric nebulizer was used for lead detection. The ICP OES condition used the following: $1.3 \mathrm{~kW} \mathrm{RF}$ power; argon gas; $15 \mathrm{~L} / \mathrm{min}$ plasma flow; $1.5 \mathrm{~L} / \mathrm{min}$ auxiliary flow; $0.75 \mathrm{~L} / \mathrm{min}$ nebulizer flow; $15 \mathrm{~s}$ instrument stabilization delay; $15 \mathrm{rpm}$ pump rate; $70 \mathrm{~s}$ sample uptake delay; 3replicates; $5 \mathrm{~s}$ read time; peak height read; and $30 \mathrm{~s}$ rinse time. The data are presented in $\mu \mathrm{g} / \mathrm{g}$ DW. All analyses were performed in triplicate.

Finally, removal rate $Q(\%)$ and adsorption capacity $q(\mathrm{mg} / \mathrm{g})$ were calculated using the following formula:

$$
\begin{gathered}
Q=\frac{(\mathrm{C} 0-\mathrm{C})}{\mathrm{C} 0} \times 100 \% \\
q=\frac{(\mathrm{C} 0-\mathrm{C})}{\mathrm{M}} \times V
\end{gathered}
$$

...where $C_{0}$ and $C$ are the initial and final concentrations of lead (II) (mg/L). The $V$ and $M$ are the volume of solution $(\mathrm{mL})$ and the mass of dry alga $(\mathrm{g})$, respectively.

\section{Statistical Analyses}

The concentrations of heavy metal in tested treatments were presented as the mean $\pm \mathrm{SD}$. The differences between exposure and control groups were tested for significance using one-way analysis of variance (ANOVA). When the ANOVAs were significant, pairwise comparison with the Tukey's honestly significant difference. A post-hoc test was then applied to detect significant differences between the exposure concentrations and the control. The $p$-values less than 0.05 were considered to be statistically significant.

\section{Results and Discussion}

\section{Algae Growth}

The results showed that Scenedesmus sp. grew well in COMBO medium and reached maximal concentration after seven days of incubation. The corresponding biomass growth pattern of Scenedesmus sp. is shown in 
Fig. 2a). All tests reached the stationary growth phase at about the same time (seven days). Cell density in the CT treatment increased from $5 \times 10^{3}$ to $4 \times 10^{6}$ after one-week culture. $\mathrm{Pb}$ induced differently on algal growth. $\mathrm{Pb}$ at low concentration from 0.05 to $0.5 \mathrm{mg} / \mathrm{L}$ did not induce the growth of Scenedesmus sp., but at the concentration of $1 \mathrm{mg} / \mathrm{L}$ or higher $\mathrm{Pb}$, it caused a significant decrease on the cell concentration of Scenedesmus sp. When the $\mathrm{Pb}^{2+}$ concentration increased from 0 to $0.5 \mathrm{mg} / \mathrm{L}$, the biomass is constant (Fig. 2a). However, a further increase of $\mathrm{Pb}^{2+}$ concentration to $10 \mathrm{mg} / \mathrm{L}$ resulted in a sharp decrease of biomass concentration.

Growth inhibition increased as the $\mathrm{Pb}$ concentration rose to $1 \mathrm{mg} / \mathrm{L}$ or higher. The $\mathrm{EC}_{50}$ values of lead for the growth inhibition of Scenedesmus sp. (after 1 week) were $4.76 \mathrm{mg} / \mathrm{L}$. $\mathrm{Pb}$ and caused significant effects and dose-dependent increases on the growth of Scenedesmus sp. Significant differences from the control growth rates were detected at the concentration of $1 \mathrm{mg} / \mathrm{L}$ or higher in Scenedesmus sp. Lead at the concentration of $10 \mathrm{mg} / \mathrm{L}$ inhibited completely the growth of Scenedesmus sp. (Fig. 2b).

Previous studies have demonstrated that $\mathrm{Pb}$ is not necessary for algae growth or respiration. $\mathrm{Pb}$ is easily accumulated by green algae and thus becomes a toxic
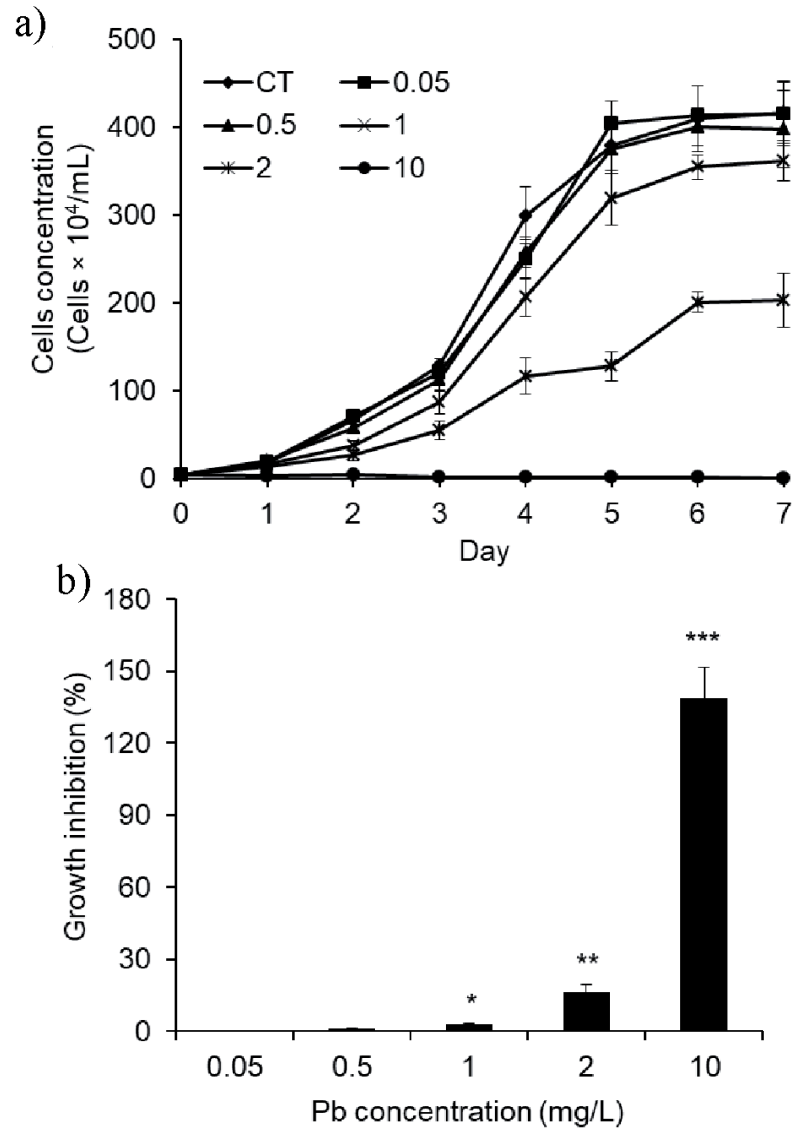

Fig. 2. Growth pattern a) and growth inhibition b) of Scenedesmus sp. exposure to different $\mathrm{Pb}$ concentrations; asterisks indicate significant differences; Anova test $(*, P<0.05$; **, $P<0.01$; ***, $P<0.001)$. influence [17, 18]. When the green alga Stichococcus bacillaris is exposed to different concentrations of $\mathrm{Pb}$, Pawlik-Skowrońska (2002) [17] reported that the growth of $S$. bacillaris was inhibited at a $\mathrm{Pb}$ concentration of $25 \mu \mathrm{mol} / \mathrm{L}$. In addition, De Schamphelaere et al. (2014) [19] found that the toxicity of $\mathrm{Pb}$ to green alga was dependent on algal species, and Pseudokirchneriella subcapitata was 4 times more sensitive to $\mathrm{Pb}$ than Chlorella kesslerii, with Chlamydomonas reinhardtii in-between. The results of this study agree well with previous observations by Ouyang et al. (2012) [18], who reported that some heavy metals including $\mathrm{Cu}, \mathrm{Cr}, \mathrm{Zn}$, $\mathrm{Cd}$ and $\mathrm{Pb}$ significantly inhibited the growth of green algae. The effects of these five metals on the growth of green algae were dependent both on concentration and exposure time.

\section{Lipid Accumulation}

$\mathrm{Pb}$ metal ion had great influence on algal growth and lipid production of Scenedesmus sp. $\mathrm{Pb}$ at the concentration of $0.05 \mathrm{mg} / \mathrm{L}$ did not influence lipid production. A further increase of $\mathrm{Pb}(0.5$ and $1 \mathrm{mg} / \mathrm{L})$ led to a significant increase in total lipid production. However, $\mathrm{Pb}$ at the concentration of $10 \mathrm{mg} / \mathrm{L}$ drastic decreased in total lipid production (Fig. 3). The maximum total lipid content of $31.1 \%$ and $30.8 \%$ were both obtained at $\mathrm{Pb}$ concentrations of 0.5 and $1 \mathrm{mg} / \mathrm{L}$, respectively. The total lipid content of the tested alga species in this study are comparable with the previous reported in other green algae such as Scenedesmus sp. [20] and Monoraphidium sp. [21].

Previous studies have demonstrated that lipid production from algae has increased significantly under heavy metal stress conditions. The total lipid content and lipid productivity of the green alga Scenedesmus sp. increased $28 \%$ and $30 \%$, respectively, in the presence of iron, magnesium and calcium with the addition of EDTA during cultivation [20]. Che et al. (2015) [21] reported

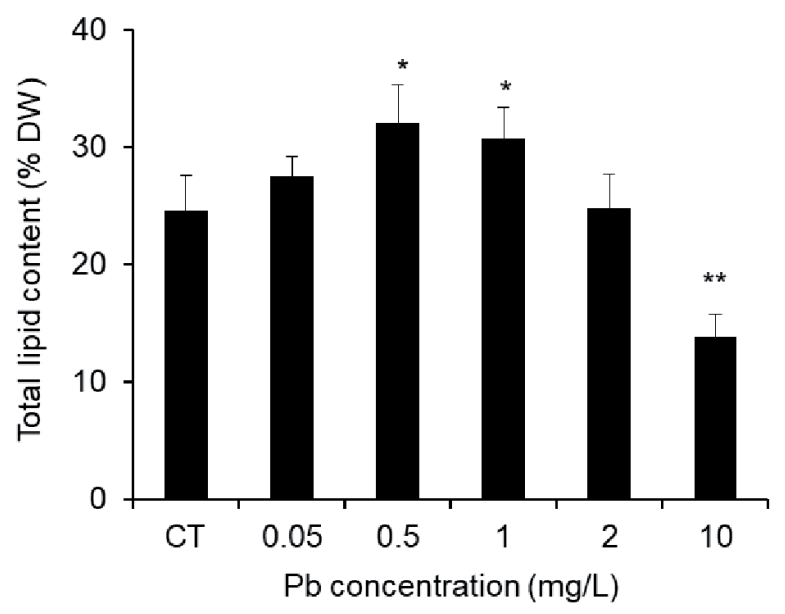

Fig. 3. Total lipid content of Scenedesmus sp. exposure to different $\mathrm{Pb}$ concentrations. 
that the effect of iron on green alga Monoraphidium sp. FXY-10, and the biomass and lipid productivity of microalgae exhibited an increasing tendency with the concentrations of iron ion augmenting. Liu et al. (2008) [22] also reported the effect of iron on C. vulgaris and the total lipid content was raised up to $56.6 \%$. Heavy metals like cadmium, copper and zinc are known to increase the total lipid content of the flagellate eukaryotes Euglena gracilis or in green alga Chlorella sp. [23, 24]. Yang et al. (2015) [23] found that the total lipid content of microalgae $C$. minutissima significantly increased by $21 \%$ and $94 \%$, respectively, with the addition of cadmium and copper. In this work, appropriate $\mathrm{Pb}^{2+}$ concentrations have enhanced lipid production, but an excessively high $\mathrm{Pb}^{2+}$ in the culture medium had an inhibitory effect on the growth and lipid production of Scenedesmus sp. These results are in line with previous observations that appropriate concentrations of metal ion were beneficial for biomass production and lipid accumulation, but higher concentrations may be toxic to green algae [21].

\section{Heavy Metal Removal and Accumulation}

The $\mathrm{Pb}$ removal capacity and intracellular accumulation of $\mathrm{Pb}$ in living Scenedesmus sp. were investigated at different initial metal concentrations for a period of 7 days (Fig. 4). Results showed that metal removal rate was higher at higher initial metal concentrations up to $2 \mathrm{mg} / \mathrm{L}$. Scenedesmus sp. attained a $\mathrm{Pb}$ removal rate of $70 \%$ at the lowest initial metal concentration tested $(0.05 \mathrm{mg} / \mathrm{L})$; the maximum removal rates $(83.5-84.2 \%)$ were observed in the treatment with 1 and $2 \mathrm{mg} / \mathrm{L}$ of $\mathrm{Pb}$. When exposed to the highest concentration $(10 \mathrm{mg} / \mathrm{L})$, a significant decrease of $\mathrm{Pb}$ removal capacity was observed (Fig. 4a). It is probable that the inhibition on growth of Scenedesmus sp. has resulted in a significant reduction of removal capacity of $\mathrm{Pb}$ in the treatment with $10 \mathrm{mg} / \mathrm{L}$.

The accumulation of $\mathrm{Pb}$ in living cells of Scenedesmus sp. after seven days' exposure to different concentrations of $\mathrm{Pb}$ is shown in Fig. 4b). Results showed that intracellular $\mathrm{Pb}$ concentration had a positive correlation with the initial metal concentration. The lowest $\mathrm{Pb}$ concentration $(0.93 \mathrm{mg} / \mathrm{g} \mathrm{DW})$ was observed in the treatment with $0.05 \mathrm{mg} / \mathrm{L}$ and the highest $\mathrm{Pb}$ concentration (13.6 mg/g DW) was recorded in the treatment with $10 \mathrm{mg} / \mathrm{L}$.

A previous study has shown that Scenedesmus spp. and Chlorella spp. have the ability to remove $\mathrm{Pb}$ up to $89 \%$ from aqueous solution [25]. However, the removal rate of metal ions by microalgae depend on variables such as initial concentration, exposure duration and target species. Algae uptake metals both passively and actively; some metals such as $\mathrm{Pb}$ and strontium ( $\mathrm{Sr}$ ) may be passively adsorbed by charged polysaccharides in cell wall and intracellular matrix, whereas others (e.g., Zn, Cd) are taken up actively against a large intracellular concentration of gradients [26]. Chen et al. (2010) [27] invoked a feedback mechanism involving multiple transporters as the presence of hardness cation or other metal ions such as copper $(\mathrm{Cu})$ and $\mathrm{Ni}$ to explain their observations of increasing $\mathrm{Pb}$ bioaccumulation in the green alga $C$. reinhardtii. In general, algae uptake metal via the two main mechanisms: adsorption on to the cell surface, and (a slower) active uptake into the cytoplasm [28]. However, Flouty and Estephane (2012) [29] found that synergistic and antagonistic effects between $\mathrm{Cu}$ and $\mathrm{Pb}$ were observed in binary metal systems, which implies that the bioaccumulation process is much more dynamic. $\mathrm{Pb}^{2+}$ uptake in green alga is thought to occur via $\mathrm{Ca}^{2+}$ pathway. Since $\mathrm{Pb}$ can mimic $\mathrm{Ca}$, a reasonable explanation for the increased $\mathrm{Pb}^{2+}$ uptake might be that $\mathrm{Pb}^{2+}$ could block the $\mathrm{Ca}^{2+}$-dependent $\mathrm{Pb}^{2+}$ efflux system [30]. The present study indicated that Scenedesmus sp. could uptake and remove $\mathrm{Pb}$ efficiently from aqueous solution at low concentrations. Higher $\mathrm{Pb}$ concentrations caused an adverse effect on cell growth and consequently decreased the removal capacity. The results of the present study were in line with previous reports that Scenedesmus sp. is able to accumulate metals to some extend depending on the concentration of the metal and on the time of contact of algae with the metal [28]. Further studies are needed to better

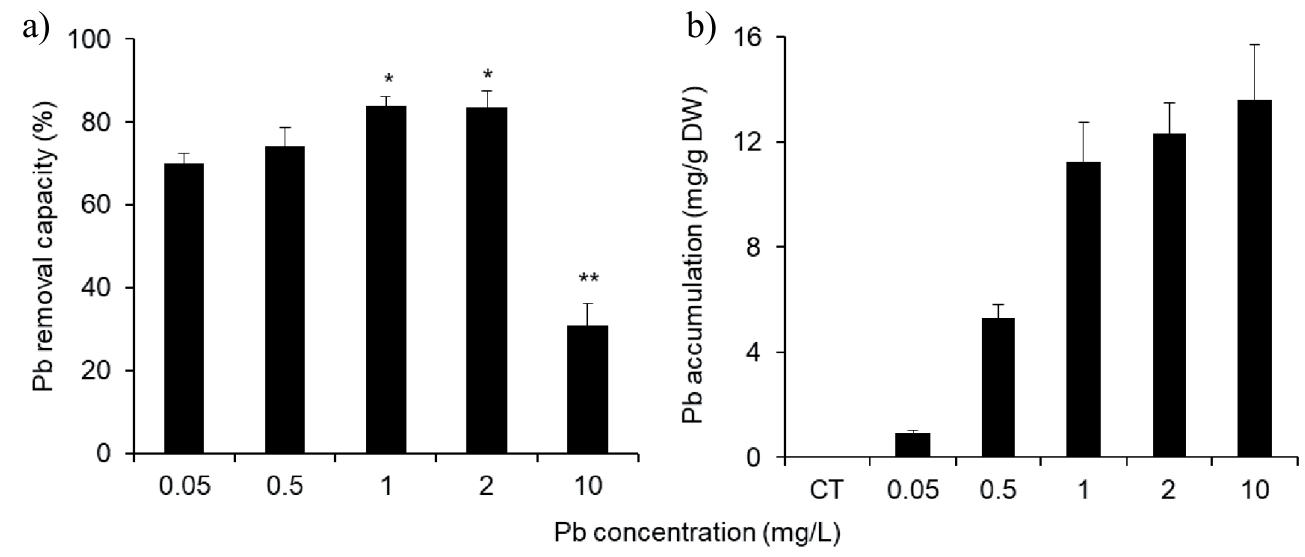

Fig. 4. Pb removal capacity a) and accumulation by Scenedesmus sp. b). 
understand the bioaccumulation of mechanisms of $\mathrm{Pb}$ in microalgae.

\section{Conclusions}

The present study indicated that living biomass of Scenedesmus sp. exhibited the ability to biosorb and bioaccumulate $\mathrm{Pb}$, and has the potential for lipid production. Initial metal ion and biomass concentrations had an influential effect on $\mathrm{Pb}$ uptake and removal. $\mathrm{Pb}$ at high concentration could prove to be toxic to the green algae and consequently decrease removal rate as well as reduce total lipid production. However, at a suitable concentration of $\mathrm{Pb}$ in water, Scenedesmus sp. exhibited a high removal efficiency and enhanced total lipid content. These results are very promising for a potential application of these microorganisms as an efficient and economic biomaterial for wastewater treatment and biofuel production based on tropical microalgae.

\section{Acknowledgements}

This work was supported by the Basic Research Foundation of the Institute of Tropical Biology.

\section{Conflict of Interest}

The authors declare no conflict of interest.

\section{References}

1. ZERAATKAR A.K., AHMADZADEH H., TALEBI A.F., MOHEIMANI N.R., MCHENRY M.P. Potential use of algae for heavy metal bioremediation, a critical review. Journal of Environmental Management, 181, 817, 2016.

2. MASON L.H., HARP J.P., HAN D.Y. Pb neurotoxicity: neuropsychological effects of lead toxicity. BioMed Research International, 840547, 1, 2014.

3. AL-HOMAIDAN A.A., AL-HOURI H.J., AL-HAZZANI A.A., ELGAALY G., MOUBAYED N.M.S. Biosorption of copper ions from aqueous solutions by Spirulina platensis biomass. Arabian Journal of Chemistry, 7 (1), 57, 2014.

4. XIN L., HONG-YING H., JIA Y. Lipid accumulation and nutrient removal properties of a newly isolated freshwater microalga, Scenedesmus sp. LX1, growing in secondary effluent. New Biotechnology, 27 (1), 59, 2010.

5. KONG Q.-X., LI L., MARTINEZ B., CHEN P., RUAN $\mathrm{R}$. Culture of microalgae Chlamydomonas reinhardtii in wastewater for biomass feedstock production. Applied biochemistry and Biotechnology, 160 (1), 9, 2010.

6. KUMAR K.S., DAHMS H.U., WON E.J., LEE J.S., SHIN K.H. Microalgae - A promising tool for heavy metal remediation. Ecotoxicology and Environmental Safety, 113, 329, 2015.

7. CHEN J., LI J., DONG W., ZHANG X., TYAGI R.D., DROGUI P., SURAMPALLI R.Y. The potential of microalgae in biodiesel production. Renewable and Sustainable Energy Reviews, 90, 336, 2018.
8. XIN L., HONG-YING H., KE G., YING-XUE S. Effects of different nitrogen and phosphorus concentrations on the growth, nutrient uptake, and lipid accumulation of a freshwater microalga Scenedesmus $s p$. Bioresource technology, 101 (14), 5494, 2010.

9. TERRY P.A., STONE W. Biosorption of cadmium and copper contaminated water by Scenedesmus abundans. Chemosphere, 47 (3), 249, 2002.

10. ZHOU G.J., PENG F.Q., ZHANG L.J., YING G.G. Biosorption of zinc and copper from aqueous solutions by two freshwater green microalgae Chlorella pyrenoidosa and Scenedesmus obliquus. Environmental Science and Pollution Research, 19 (7), 2918, 2012.

11. KWON H.K., JEON J.Y., OH S.J. Potential for heavy metal (copper and zinc) removal from contaminated marine sediments using microalgae and light emitting diodes. Ocean Science Journal, 52 (1), 57, 2017.

12. DANIELL W.E., VAN TUNG L., WALLACE R.M., HAVENS D.J., KARR C.J., BICH DIEP N., CROTEAU G.A., BEAUDET N.J., DUY BAO N. Childhood lead exposure from battery recycling in Vietnam. BioMed Research International, 193715, 12015.

13. DE CARVALHO J.C., SYDNEY E.B., TESSARI L.F.A., SOCCOL C.R. Culture media for mass production of microalgae. Biofuels from Algae: Elsevier; pp 33, 2019.

14. IVERSON S.J., LANG S.L.C., COOPER M.H. Comparison of the Bligh and Dyer and Folch methods for total lipid determination in a broad range of marine tissue. Lipids, 36 (11), 1283, 2001.

15. HAN Y., WEN Q., CHEN Z., LI P. Review of Methods Used for Microalgal Lipid-Content Analysis. Energy Procedia, 12, 944, 2011.

16. DOS SANTOS R.W., SCHMIDT É.C., DE L FELIX M.R., POLO L.K., KREUSCH M., PEREIRA D.T., COSTA G.B., SIMIONI C., CHOW F., RAMLOV F., MARASCHIN M., BOUZON Z.L. Bioabsorption of cadmium, copper and lead by the red macroalga Gelidium floridanum: Physiological responses and ultrastructure features. Ecotoxicology and Environmental Safety, 105, 80, 2014.

17. PAWLIK-SKOWROŃSKA B. Correlations between toxic $\mathrm{Pb}$ effects and production of $\mathrm{Pb}$-induced thiol peptides in the microalga Stichococcus bacillaris. Environmental Pollution, 119 (1), 119, 2002.

18. OUYANG H.L., KONG X.Z., HE W., QIN N., HE Q.S., WANG Y., WANG R., XU F.L. Effects of five heavy metals at sub-lethal concentrations on the growth and photosynthesis of Chlorella vulgaris. Chinese Science Bulletin, 57 (25), 3363, 2012.

19. DE SCHAMPHELAERE K.A.C., NYS C., JANSSEN C.R. Toxicity of lead $(\mathrm{Pb})$ to freshwater green algae: development and validation of a bioavailability model and inter-species sensitivity comparison. Aquatic toxicology, 155, 348, 2014.

20. REN H.Y., LIU B.F., KONG F., ZHAO L., XIE G.J., REN N.Q. Enhanced lipid accumulation of green microalga Scenedesmus sp. by metal ions and EDTA addition. Bioresource Technology, 169, 763, 2014.

21. CHE R., HUANG L., YU X. Enhanced biomass production, lipid yield and sedimentation efficiency by iron ion. Bioresource Technology, 192, 795, 2015.

22. LIU Z.Y., WANG G.C., ZHOU B.C. Effect of iron on growth and lipid accumulation in Chlorella vulgaris. Bioresource Technology, 99 (11), 4717, 2008.

23. YANG J., CAO J., XING G., YUAN H. Lipid production combined with biosorption and bioaccumulation of cadmium, copper, manganese and zinc by oleaginous 
microalgae Chlorella minutissima UTEX2341. Bioresource Technology, 175, 537, 2015.

24. SIBI G., SHETTY V., MOKASHI K. Enhanced lipid productivity approaches in microalgae as an alternate for fossil fuels - A review. Journal of the Energy Institute, 89 (3), 330, 2016

25. LI Y., SONG S., XIA L., YIN H., MEZA J.V.G., JU W. Enhanced $\mathrm{Pb}$ (II) removal by algal-based biosorbent cultivated in high-phosphorus cultures. Chemical Engineering Journal, 361, 167, 2019.

26. FATHI A.A. Toxicological response of the green alga Scenedesmus bijuga to mercury and lead. Folia Microbiologica, 47 (6), 667, 2002.

27. CHEN Z., ZHU L., WILKINSON K.J. Validation of the biotic ligand model in metal mixtures: bioaccumulation of lead and copper. Environmental Science and Technology, 44 (9), 3580, 2010.
28. MONTEIRO C.M., CASTRO P.M.L., MALCATA F.X. Metal uptake by microalgae: underlying mechanisms and practical applications. Biotechnology progress, 28 (2), 299, 2012.

29. FLOUTY R., ESTEPHANE G. Bioaccumulation and biosorption of copper and lead by a unicellular algae Chlamydomonas reinhardtii in single and binary metal systems: A comparative study. Journal of Environmental Management, 111, 106, 2012.

30. FLOUTY R., KHALAF G. Role of $\mathrm{Cu}$ and $\mathrm{Pb}$ on $\mathrm{Ni}$ bioaccumulation by Chlamydomonas reinhardtii: Validation of the biotic ligand model in binary metal Mixtures. Ecotoxicology and Environmental Safety, 113, 79, 2015. 
